\title{
Calcium carbonate suppresses haem toxicity markers without calcium phosphate side effects on colon carcinogenesis
}

\author{
Ossama Allam, Diane Bahuaud, Sylviane Taché, Nathalie Naud, Denis E. Corpet and \\ Fabrice H. F. Pierre* \\ Université de Toulouse, UMR 1089 Xénobiotiques, INRA, ENVT, 23 Capelles, F-31076 Toulouse, France \\ (Received 19 March 2010 - Revised 27 July 2010 - Accepted 16 August 2010 - First published online 7 December 2010)
}

\begin{abstract}
Red meat intake is associated with an increased risk of colorectal cancer. We have previously shown that haemin, Hb and red meat promote carcinogen-induced preneoplastic lesions, aberrant crypt foci (ACF), in the colon of rats. We have also shown that dietary calcium phosphate inhibits haemin-induced promotion and normalises faecal lipoperoxides and cytotoxicity. Unexpectedly, high-calcium phosphate control diet-fed rats had more preneoplastic lesions in the colon than low-Ca control diet-fed rats. The present study was designed to find a Ca supplementation with no adverse effect, by testing several doses and types of Ca salts. One in vitro study and two short-term studies in rats identified calcium carbonate as the most effective Ca salt to bind haem in vitro and to decrease faecal biomarkers previously associated with increased carcinogenesis: faecal water cytotoxicity and thiobarbituric acid-reactive substances. A long-term carcinogenesis study in dimethylhydrazine-injected rats demonstrated that a diet containing $100 \mu \mathrm{mol} / \mathrm{g}$ calcium carbonate did not promote ACF, in contrast with a previously tested calcium phosphate diet. The results suggest that calcium carbonate, and not calcium phosphate, should be used to reduce haem-associated colorectal cancer risk in meat eaters. They support the concept that the nature of the associated anion to a protective metal ion is important for chemoprevention.
\end{abstract}

Key words: Red meat: Haem: Calcium: Colorectal cancer: Prevention

Red and processed meat consumption increases the risk of colorectal cancer, according to meta-analyses of epidemiological studies ${ }^{(1,2)}$. In its 2007 report, the World Cancer Research Fund panel judges that the evidence that red meat and processed meat are a cause of colorectal cancer is convincing,(3). The panel thus recommends: 'Limit intake of red meat and avoid processed meat'. Several meat components have been speculated to explain why meat eaters are at a higher risk for colorectal cancer. Meat cooked at a high temperature contains mutagenic heterocyclic amines that induce colon, mammary and prostate tumours in rodents and monkeys ${ }^{(4)}$. However, heterocyclic amines might not play an important role in colorectal cancer incidence, since (i) chicken intake is a major contributor of heterocyclic amines, but it is not associated with the risk $^{(5)}$, and (ii) doses of heterocyclic amines that induce cancer in animals are 1000-100000 times higher than doses ingested by humans ${ }^{(6)}$. Red meat enhances the formation of putative carcinogenic $N$-nitroso compounds in human and rodent faeces ${ }^{(7-9)} . N$-nitroso compounds level is associated with the promotion of colon carcinogenesis by cured meat ${ }^{(10)}$. But $N$-nitroso compounds brought into rat faeces by a bacon-based diet do not initiate or promote preneoplastic lesions in the colon of rats ${ }^{(11)}$. Red meat also contains haem, the Fe-bearing prosthetic group of myoglobin. Intake of haem Fe is associated with an increased risk of colon cancer among women of the Iowa Women's Health Study ${ }^{(12)}$. Intake of black pudding, a blood sausage overloaded with high haem Fe, is associated with an increased risk of colorectal cancer among women of the Swedish Mammography Cohort ${ }^{(13)}$.

Experimental animal studies support the hypothesis that haem Fe promotes colorectal carcinogenesis ${ }^{(14)}$. We have shown that dietary haem, in the form of haemin (haem stabilised by a $\mathrm{Cl}$ atom, also called ferriprotoporphyrin IX chloride), Hb or red meat, promotes putative precancerous lesions, aberrant crypt foci (ACF) and mucin-depleted foci (MDF), in the colon of rats fed a low-Ca diet ${ }^{(15-17)}$. This haem-induced promotion is associated with increased lipoperoxidation and cytotoxicity of faecal water, and linked to urinary 1,4-dihydroxynonane mercapturic acid excretion, a fat peroxidation biomarker ${ }^{(18)}$. The addition of calcium

Abbreviations: ACF, aberrant crypt foci; MDF, mucin-depleted foci; TBARS, thiobarbituric acid-reactive substances. 
phosphate to the diet inhibits haemin-induced lipoperoxidation, cytotoxicity and promotion of carcinogenesis in rats $^{(17)}$, and we can explain the lack of effect of meat diets on colon carcinogenesis in previous study ${ }^{(19)}$ by a high concentration of $\mathrm{Ca}$ in the diet. The addition of calcium phosphate to beef meat diet fully prevents red meat promotion of colon carcinogenesis, but, unexpectedly, the rats fed the no-meat high-calcium phosphate high-fat diet had more ACF and more MDF than the rats fed the no-meat low-calcium phosphate diet ${ }^{(16)}$. In the absence of meat, dietary calcium phosphate appears to promote carcinogenesis in this rodent model, which precludes its use in human volunteers.

The present study was designed to determine a Ca supplementation with no adverse effect by testing different types of $\mathrm{Ca}$ salts and finding the minimum effective Ca dose.

\section{Materials and methods}

\section{Animals and diets}

Eighty-five Fischer 344 female rats were purchased at 4 weeks of age from Iffa Credo (St Germain sur l'Arbresle, France). Animal care was in accordance with the guidelines of the European Council on animals used in experimental studies. The animal colony and staff got official agreement no. 31-121 for animal studies by the French government.

Short-term studies. Two short-term studies were designed to find the most effective $\mathrm{Ca}$ salt and the minimum effective $\mathrm{Ca}$ dose to suppress early biomarkers of haem toxicity. Rats were housed individually in metabolism cages. The room was kept at a temperature of $22^{\circ} \mathrm{C}$ on a $12 \mathrm{~h}$ light-dark cycle. After $5 \mathrm{~d}$ of acclimatisation to the AIN76-powdered diet, rats were provided with the experimental diets. Body weights and food intake were monitored at the start and at the end of each study. In the first study, forty rats were randomly allocated to eight dietary groups (five rats per group) for 1 week. Faeces were collected at day 7 and were frozen at $-20^{\circ} \mathrm{C}$. Animals were killed $7 \mathrm{~d}$ after the start of the experimental diets. In the second study, twenty-five rats were randomly allocated to five dietary groups (five rats per group) for 2 weeks. Faeces were collected at day 14 and were frozen at $-20^{\circ} \mathrm{C}$. Animals were killed $14 \mathrm{~d}$ after the start of the experimental diets.

Long-term study. A 3-month study was designed to test the hypothesis that the minimum effective dose of the most effective Ca salt, selected from the results of the short-term studies, does not promote carcinogenesis in rats. Twenty rats were housed in pairs in stainless steel wire-bottomed cages. The room was kept at a temperature of $22^{\circ} \mathrm{C}$ on a $12 \mathrm{~h}$ light-dark cycle. Rats were allowed $7 \mathrm{~d}$ of acclimatisation to the room and to the control diet, before being injected intraperitoneally with the carcinogen 1,2-dimethylhydrazine $(190 \mathrm{mg} / \mathrm{kg}$ body weight; Sigma Chemical,
St Quentin, France) in $\mathrm{NaCl}(9 \mathrm{~g} / \mathrm{l})$. In most published studies, several carcinogen injections are administered to rats. We reasoned here that the first shot initiates carcinogenesis, but that the following shots would promote carcinogenesis, blurring diet-induced promotion. We thus chose a single-shot protocol, following Karkare et al. ${ }^{(20)}$. After $7 \mathrm{~d}$, rats were randomly allocated to two groups of ten, and allowed free access to calcium carbonate-based diets for $94 \mathrm{~d}$. We chose to initiate with the carcinogen in all rats, since the study was designed to show dietary promotion of carcinogenesis.

Diets. Experimental diets shown in Table 1 were based on a modified standard AIN76 diet ${ }^{(21)}$, prepared and formulated in a powdered form by UPAE (INRA, Jouy-enJosas, France). For the first short-term study, high-beef meat diets were formulated to contain $60 \%$ meat $(\mathrm{w} / \mathrm{w}$, freeze dried, $0.6 \mathrm{mmol}$ haem $/ \mathrm{g}$ of meat), and dibasic calcium phosphate was included in all the diets at a low concentration of $20 \mu \mathrm{mol} / \mathrm{g}$. To determine the minimum effective dose of calcium phosphate, the effect of six concentrations of Ca was tested in six groups of rats fed the low-Ca beef meat diet supplemented with calcium phosphate (doses range: $33-250 \mu \mathrm{mol} / \mathrm{g}$, diet names: Phos33...Phos250). To compare the efficacy of calcium phosphate with other salts, the effect of two Ca salts was tested in two groups of rats fed a calcium carbonate (Carb250) or calcium gluconate (Gluc250) diet at the highest tested dose $(250 \mu \mathrm{mol} / \mathrm{g})$. For the second short-term study, the effect of calcium carbonate was tested in five groups of rats fed a $\mathrm{Hb}$ diet, supplying $0.6 \mathrm{mmol} / \mathrm{g}$ haem to mimic the $60 \%$ beef meat diet, supplemented with calcium carbonate (doses range: $33-155 \mu \mathrm{mol} / \mathrm{g}$, diet names: Carb33 ... Carb155). For the long-term carcinogenesis study, two experimental diets were formulated to contain two levels of calcium carbonate $(33$ and $100 \mu \mathrm{mol} / \mathrm{g}$, diet names: control diet and Carb100) added into the control low-calcium phosphate diet.

\section{Preparation of faecal water}

Faecal pellets were collected for $24 \mathrm{~h}$ under each cage (one rat/cage, short-term studies; two rats/cage, long-term study), thus leading to five samples per diet. Freeze-dried faeces were used to calculate dry faecal mass and to prepare faecal water by adding $1 \mathrm{ml}$ of sterilised water to $0.3 \mathrm{~g}$ of dry faeces. Samples were then incubated at $37^{\circ} \mathrm{C}$ for $1 \mathrm{~h}$, stirring thoroughly every $20 \mathrm{~min}$, followed by centrifugation at $20000 \boldsymbol{g}$ for $10 \mathrm{~min}$. The aqueous phase was re-centrifuged at the same speed and duration, and the subsequent supernatant (faecal water) was collected and stored at $-20^{\circ} \mathrm{C}$ until use.

\section{Thiobarbituric acid-reactive substances and haem assay}

Thiobarbituric acid-reactive substances (TBARS) were measured in faecal water according to Ohkawa et al. ${ }^{(22)}$, 
Table 1. Formulation of diets $(\mathrm{g} / 100 \mathrm{~g})^{\star}$

\begin{tabular}{|c|c|c|c|c|c|c|c|c|c|c|c|c|c|c|c|}
\hline & \multicolumn{8}{|c|}{ First short-term study: beef meat-based diets } & \multicolumn{5}{|c|}{ Second short-term study: casein-based diets } & \multicolumn{2}{|c|}{ Long-term study } \\
\hline & Phos20 & Phos33 & Phos55 & Phos90 & Phos 150 & Phos250 & Carb250 & Gluc250 & Carb33 & Carb55 & Carb80 & Carb110 & Carb155 & $\begin{array}{c}\text { Control diet } \\
\text { (Carb33) }\end{array}$ & Carb100 \\
\hline Beef & $60 \cdot 0$ & $60 \cdot 0$ & $60 \cdot 0$ & $60 \cdot 0$ & $60 \cdot 0$ & $60 \cdot 0$ & $60 \cdot 0$ & $60 \cdot 0$ & 0.0 & 0.0 & 0.0 & 0.0 & 0.0 & 0.0 & 0.0 \\
\hline $\mathrm{Hb}$ & 0.0 & 0.0 & 0.0 & 0.0 & 0.0 & 0.0 & 0.0 & 0.0 & 0.63 & 0.63 & 0.63 & 0.63 & 0.63 & 0.0 & 0.0 \\
\hline Safflower oil & $5 \cdot 0$ & $5 \cdot 0$ & $5 \cdot 0$ & $5 \cdot 0$ & $5 \cdot 0$ & $5 \cdot 0$ & $5 \cdot 0$ & 5.0 & 5.0 & 5.0 & $5 \cdot 0$ & $5 \cdot 0$ & 5.0 & $5 \cdot 0$ & $5 \cdot 0$ \\
\hline Lard & 0.0 & 0.0 & 0.0 & 0.0 & 0.0 & 0.0 & 0.0 & 0.0 & $5 \cdot 0$ & $5 \cdot 0$ & $5 \cdot 0$ & $5 \cdot 0$ & $5 \cdot 0$ & $5 \cdot 0$ & $5 \cdot 0$ \\
\hline Casein† & 5.9 & 5.9 & 5.9 & 5.9 & 5.9 & 5.9 & 5.9 & 5.9 & $59 \cdot 0$ & $59 \cdot 0$ & $59 \cdot 0$ & $59 \cdot 0$ & $59 \cdot 0$ & $59 \cdot 0$ & $59 \cdot 0$ \\
\hline Maize starch & $6 \cdot 0$ & $6 \cdot 0$ & $6 \cdot 0$ & $6 \cdot 0$ & $6 \cdot 0$ & $6 \cdot 0$ & $6 \cdot 0$ & $6 \cdot 0$ & $7 \cdot 0$ & $7 \cdot 0$ & $7 \cdot 0$ & $7 \cdot 0$ & $7 \cdot 0$ & $7 \cdot 0$ & $7 \cdot 0$ \\
\hline Sucrose & $12 \cdot 8$ & $12 \cdot 6$ & $12 \cdot 3$ & 11.9 & $11 \cdot 1$ & $9 \cdot 7$ & $10 \cdot 6$ & 2.5 & $16 \cdot 0$ & $15 \cdot 8$ & 15.5 & $15 \cdot 2$ & 14.8 & 16 & 15 \\
\hline Cellulose & $5 \cdot 0$ & $5 \cdot 0$ & $5 \cdot 0$ & $5 \cdot 0$ & $5 \cdot 0$ & $5 \cdot 0$ & 5.0 & 5.0 & $5 \cdot 0$ & $5 \cdot 0$ & $5 \cdot 0$ & $5 \cdot 0$ & $5 \cdot 0$ & 5 & 5 \\
\hline Met & 0.3 & 0.3 & 0.3 & 0.3 & 0.3 & 0.3 & 0.3 & 0.3 & 0.3 & 0.3 & 0.3 & 0.3 & 0.3 & 0.3 & 0.3 \\
\hline Mineral mixł & 3.5 & 3.5 & 3.5 & 3.5 & 3.5 & 3.5 & 3.5 & 3.5 & 3.5 & 3.5 & 3.5 & 3.5 & 3.5 & 3.5 & 3.5 \\
\hline Vitamin mixł & $1 \cdot 0$ & 1.0 & 1.0 & 1.0 & 1.0 & $1 \cdot 0$ & 1.0 & 1.0 & 1.0 & 1.0 & $1 \cdot 0$ & 1.0 & 1.0 & $1 \cdot 0$ & 1.0 \\
\hline Choline bitartrate & 0.2 & 0.2 & 0.2 & 0.2 & 0.2 & 0.2 & 0.2 & 0.2 & 0.2 & 0.2 & 0.2 & 0.2 & 0.2 & 0.2 & 0.2 \\
\hline Calcium phosphate & 0.2 & 0.4 & 0.7 & $1 \cdot 1$ & 1.9 & $3 \cdot 3$ & 0.2 & 0.2 & 0.2 & 0.2 & 0.2 & 0.2 & 0.2 & 0.2 & 0.2 \\
\hline Calcium carbonate & 0.0 & 0.0 & 0.0 & 0.0 & 0.0 & 0.0 & $2 \cdot 5$ & 0.0 & 0.3 & 0.5 & 0.8 & $1 \cdot 1$ & 1.5 & 0.3 & 1.0 \\
\hline Calcium gluconate & 0.0 & 0.0 & 0.0 & 0.0 & 0.0 & 0.0 & 0.0 & $10 \cdot 6$ & 0.0 & 0.0 & 0.0 & 0.0 & 0.0 & 0.0 & 0.0 \\
\hline
\end{tabular}

* Phos20-Phos250 are low-Ca beef diets supplemented with calcium phosphate from 20 to $250 \mu \mathrm{mol} / \mathrm{g}$. Carb250 and Gluc250 are low-Ca beef diets supplemented, respectively, with calcium carbonate and calcium gluconate at $250 \mu \mathrm{mol} / \mathrm{g}$. Carb33-Carb155 are low-Ca Hb diets supplemented with calcium carbonate from 33 to $155 \mu \mathrm{mol} / \mathrm{g}$. Control diet and Carb100 low-Ca Hb diet supplemented with calcium phosphate from 33 to $100 \mu \mathrm{mol} / \mathrm{g}$. † Low-Ca casein.

¥ AlN76 mix, but $500 \mathrm{~g} / \mathrm{kg}$ of dibasic calcium phosphate were replaced by sucrose in mineral mix. 
exactly as described previously, and results are expressed as malondialdehyde equivalent ${ }^{(15)}$. Haem contents of faecal water were measured by fluorescence according to Van den Berg et al. ${ }^{(23)}$ and Sesink et al. ${ }^{(14)}$, respectively, as described previously ${ }^{(15)}$. Both TBARS and haem in faeces were measured on faecal samples from both the short-term studies.

\section{In vitro experiment}

The ability of five different Ca salts ( 1 - calcium phosphate, 2 - calcium chloride, 3 - calcium gluconate, 4 calcium carbonate, 5 - calcium lactate) to bind and to precipitate haem from bovine $\mathrm{Hb}$ solution was studied in vitro. $\mathrm{Hb}(0.36 \mathrm{mmol}$; Sigma Chemical $)$ was acidified at $\mathrm{pH} 1.4$ with $2 \mathrm{~mol} \mathrm{HCl}$ and then heated $1 \mathrm{~h}$ at $105^{\circ} \mathrm{C}$ to dissociate haem from $\mathrm{Hb}$. This solution was centrifuged at $20000 \boldsymbol{g}$ for $10 \mathrm{~min}$. Supernatant with free haem was collected.

Six concentrations of each of five Ca salts were prepared $(25,50,75,100,125$ and $150 \mathrm{mmol} / \mathrm{l})$. According to Sesink et al. ${ }^{(24)}, 1 \mathrm{ml} \mathrm{Hb}$ added to $1 \mathrm{ml} \mathrm{Ca}$ salt was incubated for $90 \mathrm{~min}$ at $37.5^{\circ} \mathrm{C}$ in the dark and mixed every $10 \mathrm{~min}$. The mixture was centrifuged for $2 \mathrm{~min}$ at $10000 \mathrm{~g}$. Supernatant $(100 \mu \mathrm{l})$ was assayed for the remaining haem after twentyfold dilution in distilled water, by absorbance being measured at $400 \mathrm{~nm}$ with a Lambda 2 spectrophotometer (PYE Unicam-PU8600 UV/VIS-spectrophotometer Philips). Different $\mathrm{Hb}$ concentrations were prepared as standard solutions: $1 / 1(100 \%), 1 / 5,1 / 10,1 / 20$ and $1 / 50$ in water. The assay was repeated three times, and the mean values were recorded.

\section{Aberrant crypt foci assay}

Rats were killed by $\mathrm{CO}_{2}$ asphyxiation in a random order at day 94 of the long-term study. Colons were excised from rats immediately post-mortem, flushed with cold Krebs solution (Sigma Chemical), opened longitudinally and fixed flat between two sheets of filter paper in $10 \%$ formalin (Sigma Chemical), marked with a two-digit blinding code. Colons picked up in random order were stained for $6 \mathrm{~min}$ in a $0.05 \%$ filtered solution of methylene blue $^{(25)}$. The number of ACF per colon and number of crypts in each ACF were counted under a light microscope at $40 \times$ magnification in duplicate by two readers, blinded for the origin of the colon.

\section{Statistical analysis}

Results were analysed using SYSTAT 10 software for Windows and reported as means and standard deviations. Long-term study data were analysed by Student's $t$ test, except ACF data that were analysed by two-way ANOVA (dietary group and reader). Short-term study data were considered first using one-way ANOVA. If a significant difference was found between the groups $(P<0.05)$, then pairwise comparisons were made with Fisher's least significant difference multiple comparison test.

The meta-analysis of the relation between calcium carbonate and colon cancer in carcinogen-injected rats was done as a sub-analysis of a study that we published in $2005^{(26)}$. From this previous meta-analysis, we selected studies where calcium carbonate had been fed to experimental groups of rats. The studies were homogeneous (Q Cochran $P>0.05$ ); we thus used the 'Fixed Effects' model, using EasyMA DOS software (2001 version) to compute data.

\section{Results}

\section{Weight and food intake during in vivo studies}

Final body weight of rats was 107 (SD 2) g after $7 \mathrm{~d}$ on the experimental diets in the first short-term study, without significant differences between the groups. Food intake was not significantly different (data not shown), but Gluc250fed rats tended to eat less than the other groups (Gluc250: $7 \cdot 2$ (SD 2.0) g/d, all other groups: $9 \cdot 1$ (SD 1.0) g/d, $P=0.09)$. No difference in body weight and diet intake between the groups was observed in the second shortterm study or in the long-term study. Mean body weights were, respectively, 166 (SD 2) g after $14 \mathrm{~d}$ and 201 (SD 8) g after $94 \mathrm{~d}$ on the experimental diets.

\section{First short-term study: thiobarbituric acid-reactive substances of faecal water}

Haem can induce the formation of peroxyl radicals in rats, which may be cytotoxic and cleave DNA in vivo. This might explain the promoting effect of haem on colon carcinogenesis. Lipid peroxidation was thus measured in faecal water by TBARS assay. Ca can prevent haeminduced promotion of colon carcinogenesis by precipitating haem in the colonic content; thus haem concentration in faecal water was measured.

Haem concentration in faecal water from beef meat-fed rats was significantly reduced in rats fed 150 and $250 \mu \mathrm{mol} / \mathrm{g}$ calcium phosphate $(P<0.01 ;$ Fig. $1(\mathrm{a}))$, but not in rats fed lower levels of calcium phosphate. Dietary calcium carbonate and $250 \mu \mathrm{mol} / \mathrm{g}$ gluconate produced the same effect on haem than calcium phosphate (Fig. 1(a)). Surprisingly, haem-induced lipid peroxidation measured by TBARS level was not significantly reduced by the calcium phosphate diets, but only the high-calcium carbonate diet decreases TBARS level in faecal water $(P<0 \cdot 01$; Fig. 1(b)).

\section{In vitro study}

Any tested concentration of calcium carbonate higher than $25 \mathrm{mmol}$ was much more effective to precipitate haem than 

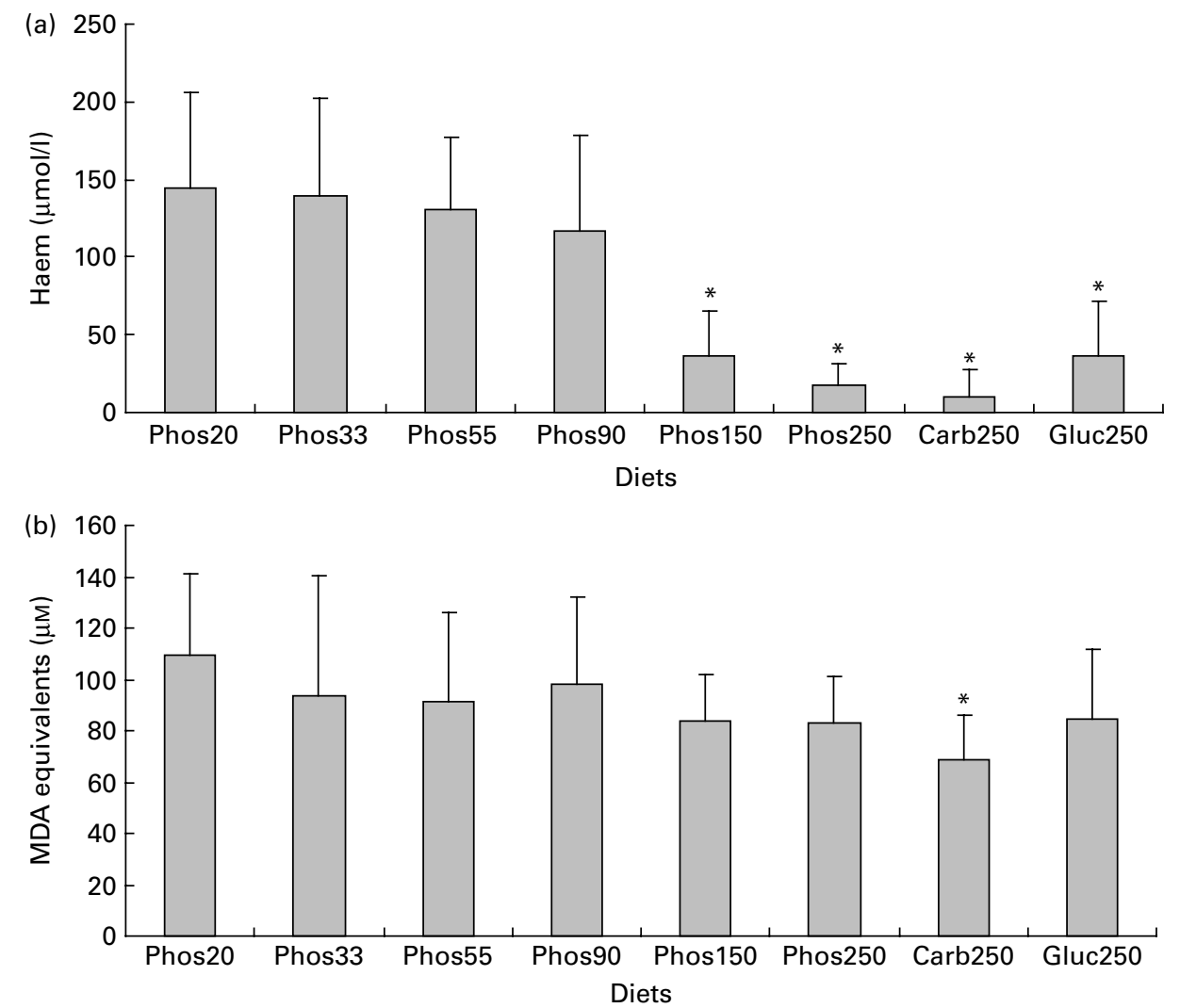

Fig. 1. Effect of diets on haem and thiobarbituric acid-reactive substances (TBARS) in faecal water after the first short-term study. (a) Haem in faecal water. (b) TBARS (malondialdehyde (MDA) equivalents) in faecal water as marker for lipid luminal peroxidation. * Mean values were significantly different from Phos20 $(P<0.01$, by Fisher's least significant difference test). Data are means, and bars are standard deviations ( $n 5$ in each group). Note: Phos20-Phos250 are low-Ca beef diets supplemented with calcium phosphate from 20 to $250 \mu \mathrm{mol} / \mathrm{g}$. Carb250 and Gluc250 are low-Ca beef diets supplemented, respectively, with calcium carbonate and calcium gluconate at $250 \mu \mathrm{mol} / \mathrm{g}$.

any other tested Ca salt. Proportion of trapped haem was more than three times higher with calcium carbonate than with calcium phosphate $(100 \mathrm{mmol})(P<0 \cdot 001$; Fig. 2$)$.

\section{Second short-term study: thiobarbituric acid-reactive substances of faecal water}

Beef meat was replaced by $\mathrm{Hb}$ in the second study diets, since we have demonstrated previously that they produce similar effects on colon carcinogenesis and on faecal water peroxidation $^{(15)}$. The high-calcium phosphate diet $(250 \mu \mathrm{mol} / \mathrm{g})$ did not prevent haem toxicity in the $7 \mathrm{~d}$ study, in contrast with our previous $50 \mathrm{~d}$ study ${ }^{(17)}$. We suggest that this duration was too short to reduce the level of TBARS; thus we chose the second short-term study to last for $14 \mathrm{~d}$. As calcium carbonate was the only effective salt against haem-induced lipid peroxidation in vivo and the only effective salt to precipitate haem in vitro, this salt was used to determine the smallest effective $\mathrm{Ca}$ dose.

Haem concentration was lower in faecal water from rats fed a diet containing at least $80 \mu \mathrm{mol} / \mathrm{g}$ calcium carbonate $(P<0.001$; Fig. 3(a)). Accordingly, diets containing at least $80 \mu \mathrm{mol} / \mathrm{g}$ calcium carbonate reduced haem-induced lipid peroxidation of faecal water $(P<0 \cdot 001$; Fig. 3(b)).

\section{Aberrant crypt foci assay}

We chose to test if a diet containing $100 \mu \mathrm{mol} / \mathrm{g}$ calcium carbonate would promote colon carcinogenesis because the second short-term study showed that a $80 \mu \mathrm{mol} / \mathrm{g}$

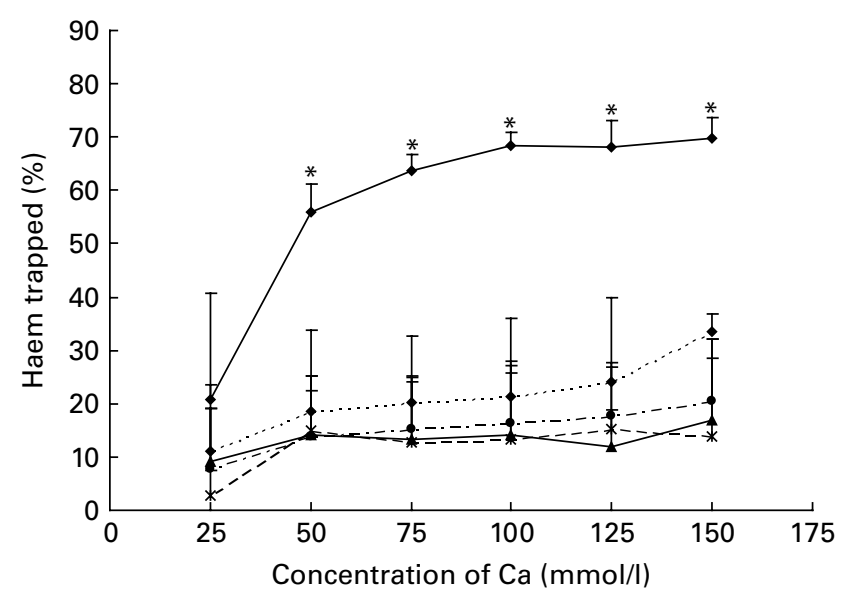

Fig. 2. Effect of Ca salts on haem solubility in vitro. Haem $(0.36 \mathrm{~mm})$ was incubated with six different concentrations of Ca salts $(150,125,100,75,50$ and $25 \mathrm{mmol} / \mathrm{l})$. Data are means, and bars are standard deviations (n 3). * Mean values were significantly different from other salts. $-\downarrow-$, Calcium carbonate; - - --, calcium phosphate; $-\boldsymbol{\Delta}-$, calcium chloride; --๑--, calcium gluconate; -*-, calcium lactate. 

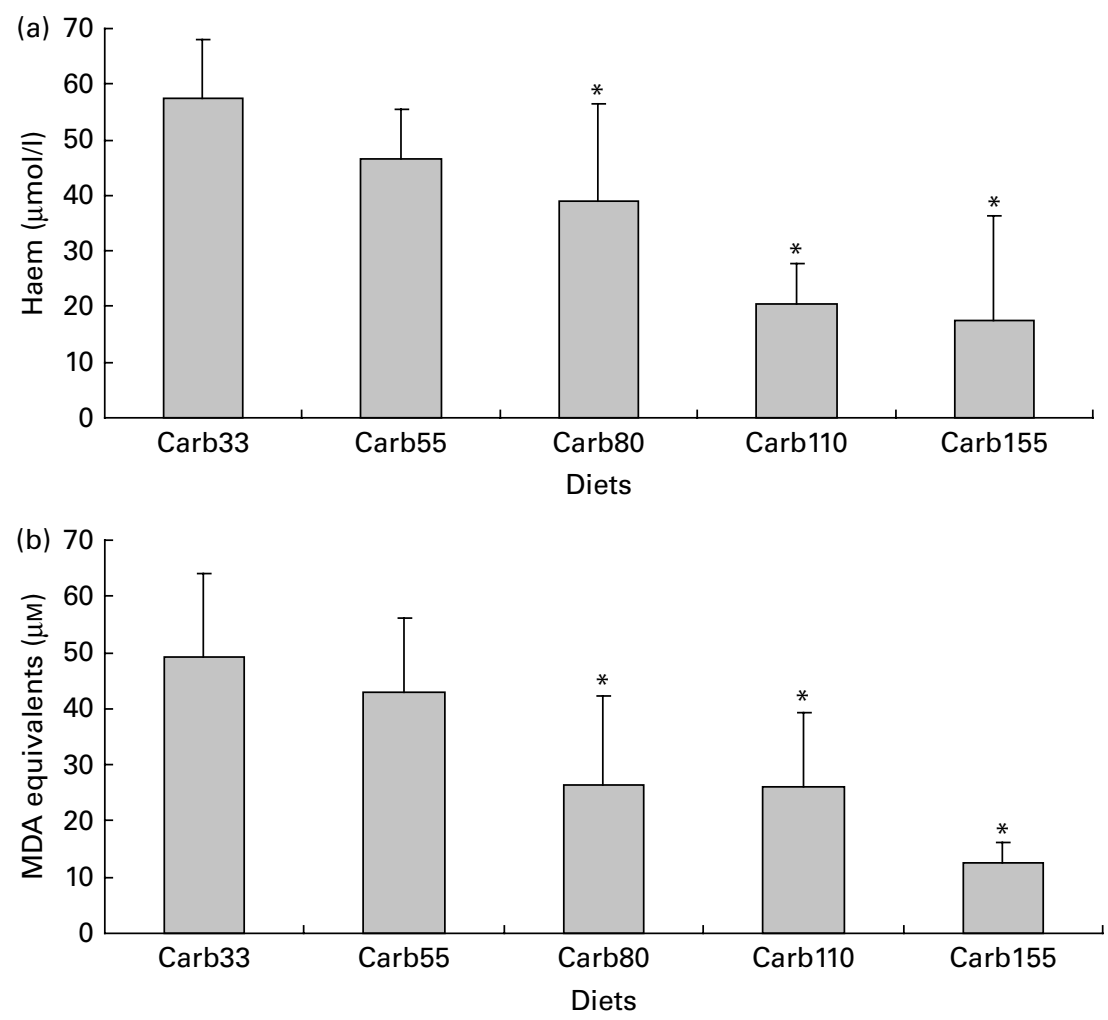

Fig. 3. Effect of calcium carbonate-based diets $(30-155 \mu \mathrm{mol} / \mathrm{g})$ on faecal water values after the second short-term study. (a) Haem concentration in faecal water ( $\mu \mathrm{mol} / \mathrm{l})$. (b) Thiobarbituric acid-reactive substances concentration in faecal water, expressed as $\mu \mathrm{mol} / \mathrm{l}$ malondialdehyde (MDA) equivalents. ${ }^{*}$ Mean values were significantly different from Carb30 by Fisher's least significant difference test $(P<0.05)$. Data are means, and bars are standard deviations $(n 5$ in each group). Note: Carb33-Carb155 are low-Ca Hb diets supplemented with calcium carbonate from 33 to $155 \mu \mathrm{mol} / \mathrm{g}$.

calcium carbonate diet reduces faecal TBARS concentration, and that $110 \mu \mathrm{mol} / \mathrm{g}$ seemed twice more potent than $80 \mu \mathrm{mol} / \mathrm{g}$ to bind faecal haem. In contrast with a calcium phosphate diet ${ }^{(16)}$, the consumption of a diet containing $100 \mu \mathrm{mol} / \mathrm{g}$ calcium carbonate for $94 \mathrm{~d}$ did not increase significantly the number of ACF per colon, $101 \mathrm{~d}$ after a dimethylhydrazine injection (Fig. 4).

\section{Discussion}

These data confirm that dietary Ca reduces faecal water lipoperoxides level, a biomarker linked with haeminduced carcinogenesis promotion. They also establish that the type of $\mathrm{Ca}$ salt is paramount in this protection, and that calcium carbonate is effective without promoting the side effect of calcium phosphate.

Red meat promotes ACF and MDF in the colon of carcinogen-induced rats, and haem-induced promotion by meat is associated with faecal water cytotoxicity and TBARS $^{(15,16)}$. The mechanism of promotion by haem is not known and may be linked to lipid peroxidation. We have explored the effect of faecal water from beef meatfed rats on normal $(\mathrm{Apc}+/+)$ and premalignant colonic cells (Apc-/+). Results show that Apc-mutated cells survive in haem-induced faecal lipoperoxides, notably 4-hydroxynonenal that is toxic to normal cells. Selection of mutated cells by cytotoxic lipoperoxides may thus explain haem-induced promotion of colon carcinogenesis ${ }^{(27)}$. $\mathrm{Ca}$ added on top of beef meat or haemin diets normalises the number of ACF and MDF at the same low level as in the control group $^{(17)}$. Calcium phosphate precipitates haem in the gut, and little haem remains available to induce lipid peroxidation $^{(17,24)}$. The trapping of haem by $\mathrm{Ca}$ thus abolishes carcinogenesis promotion. In the present study, we established that different $\mathrm{Ca}$ salts are able to precipitate haem

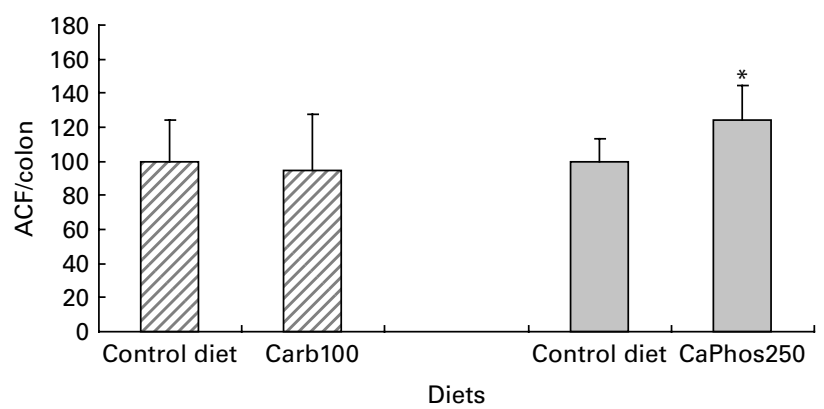

Fig. 4. Effect of calcium salts in diet on putative precancerous lesions (aberrant crypt foci (ACF)) per rat colon $101 \mathrm{~d}$ after the injection of dimethylhydrazine. Results of the present study with $100 \mu \mathrm{mol} / \mathrm{g}$ calcium carbonate are represented by $\square$. Results of the previous study with $250 \mu \mathrm{mol} / \mathrm{g}$ calcium phosphate (Pierre et al. ${ }^{(16)}$ ) are represented by $\square$. Results are expressed after normalisation of the control diet groups to $100 .{ }^{*}$ Mean values were significantly different control group. Note: the control diet was a low-Ca $\mathrm{Hb}$ diet supplemented with calcium carbonate at $33 \mu \mathrm{mol} / \mathrm{g}$. Carb100 and CaPhos250 are low-Ca $\mathrm{Hb}$ diets supplemented, respectively, with calcium carbonate $(100 \mu \mathrm{mol} / \mathrm{g})$ and calcium gluconate $(230 \mu \mathrm{mol} / \mathrm{g})$. 
in vitro and in faecal water of haem-fed rats and by consequence are able to reduce faecal water peroxidation (Figs. 1 and 2). We observed that only high concentrations of calcium phosphate were able to precipitate haem (Fig. 1(a)). Furthermore, the ability of the three tested salts (phosphate, carbonate and gluconate) to trap haem was very similar in high-Ca diets (Fig. 1(a)). However, only calcium carbonate decreased significantly the level of lipid peroxidation in faecal water (Fig. 1(b)). So, to screen more precisely the efficiency of different Ca salts, we measured the in vitro trapping of haem: only calcium carbonate precipitated haem significantly. In conclusion, the present study shows for the first time a difference of efficiency between Ca salts in vitro (Fig. 2) and in vivo, in the trapping of haem and the limitation of peroxidation (Fig. 1(b)). We have no explanation for the relatively high TBARS level in controls and in rats administered with high doses of calcium phosphate or gluconate: we speculate that the beef meat in the first study may have contained already oxidised fat or oxidising agents different from haem Fe (Fig. 1(b)).

Our previous study showed that rats consuming a highCa control diet had more ACF and more MDF than rats consuming a low-Ca control diet ${ }^{(16)}$. This promotion was observed with calcium phosphate in a high-fat diet context, but was not observed in a low-fat diet context without a clear explanation for the high-fat/low-fat discrepancy ${ }^{(17)}$. Bull et $a l .{ }^{(28)}$ also showed that the promotion of tumours by calcium phosphate was more important in $30 \%$-fat diet-fed rats than in 3\%-fat diet-fed rats. Phosphate, not $\mathrm{Ca}$, might be the promoting nutrient, an issue already discussed by Bruce et al. ${ }^{(29)}$. Since our in vitro study indicated that calcium carbonate was more effective than calcium phosphate to trap haem (Fig. 2) and since the first in vivo study indicated that a high concentration of calcium carbonate was able to precipitate haem and to limit peroxidation in vivo, we determined the lower effective dose of calcium carbonate in a second short-term study (Fig. 3). We showed that $80 \mu \mathrm{mol}$ calcium carbonate/g diet is enough to trap haem and to reduce peroxidation. The first aim of the present study was to identify the lower dose and type of $\mathrm{Ca}$ sufficient to limit the effect of haem in the colon without side effects. We thus tested the effect of an addition of $100 \mu \mathrm{mol}$ calcium carbonate $/ \mathrm{g}$ diet on the promotion of colon carcinogenesis at the level of ACF (Fig. 4). In contrast with the promoting effect of calcium phosphate at $250 \mu \mathrm{mol} / \mathrm{g}^{(16)}$, we did not observe a promoting effect of calcium carbonate on ACF. The present study shows for the first time that a $\mathrm{Ca}$ salt can inhibit the toxic effect of haem in the colon without side effect on the promotion of colon carcinogenesis.

To confirm that calcium carbonate does not promote carcinogenesis in rats, we performed a meta-analysis of published data on calcium carbonate and colon carcinogenesis (Fig. 5). Our previous meta-analysis study showed that $\mathrm{Ca}$ (all salts) modestly decreases tumour incidence in rats,

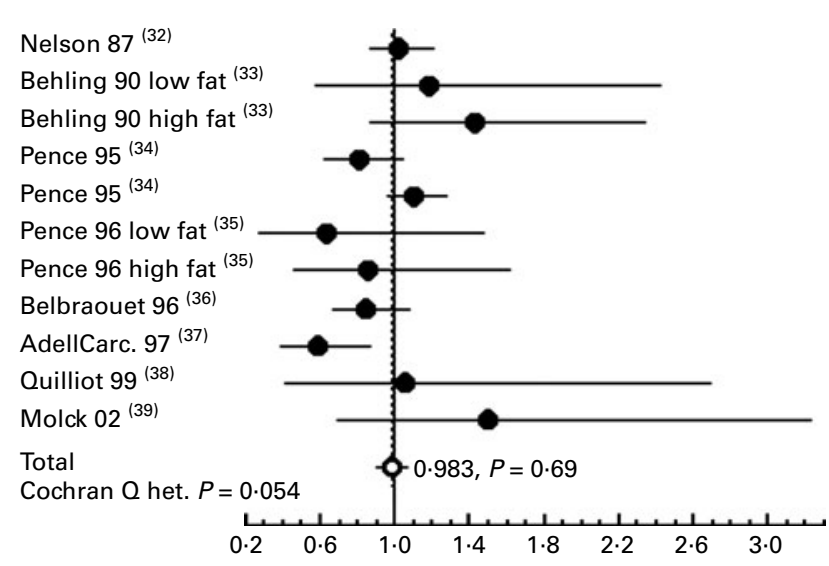

Fig. 5. Meta-analysis of the relation between calcium carbonate and colon cancer in carcinogen-injected rats. The common relative risk with $95 \% \mathrm{Cl}$ was calculated from eleven studies. The study-specific relative risk is represented by $\bullet$. The common relative risk is represented by $\bigcirc$. Horizontal lines are $95 \% \mathrm{Cl}$. References are indicated between brackets. Het., heterogeneity.

and that some Ca salts are more protective than others ${ }^{(26)}$ : calcium lactate, but not calcium phosphate, reduces chemically induced carcinogenesis. Fig. 5 shows data from a meta-analysis of eleven studies of high-calcium carbonate diets on colon carcinogenesis in chemically injected rats; the combined relative risk from all of these studies was 0.983 (95\% CI 0.902, 1.071; $P=0.69$ ), compared with low Ca controls. This meta-analysis confirms the lack of promoting side effect by calcium carbonate on colon carcinogenesis. These results on rodents are coherent with two randomised, double-blinded, placebo-controlled trials. Calcium carbonate supplementation was associated with a significant though moderate - reduction in the risk of recurrent colorectal adenomas in the Calcium Polyp Prevention Study ${ }^{(30)}$. In contrast, daily supplementation of calcium carbonate (with vitamin D) for 7 years to 36282 postmenopausal women from forty Women's Health Initiative centres had no effect on the incidence of colorectal cancer among postmenopausal women ${ }^{(31)}$. Altogether, these results suggest that calcium carbonate supplementation to neutralise haem does not bear any risk. However, chelation of dietary haem Fe bears the theoretical risk of Fe deficiency leading to anaemia: recommendations should take this in account.

The study also supports the concept that nutrients such as Ca may inhibit the toxicity associated with the excess of another nutrient like haem. This concept differs from the classical chemoprevention concept, since calcium carbonate does not reduce carcinogenesis in rats that are not fed with dietary haem. This specific Ca-preventive effect, by interaction, should be looked for in a cohort study by crossing haem and $\mathrm{Ca}$ intake with adenoma or cancer risk.

\section{Acknowledgements}

The authors disclosed no potential conflicts of interest. The present study was supported in part by the INRA, 
the DGER and the French region Midi-Pyrénées. We thank Xavier Blanc (UPAE) for the preparation of experimental diets, Raymond Gazel and Florence Blas Y. Estrada for the care of the animals. O. A. had made substantial contributions to the in vitro study, the second short-term in vivo study and the long-term study (acquisition of data, analysis and interpretation of data). D. B. had made substantial contributions to the first in vivo study (acquisition of data or analysis and interpretation of data). S. T. and N. N. had made substantial contributions to the three in vivo studies. D. E. C. and F. H. F. P. had made substantial contributions to the conception and design of the present study and by drafting the article.

\section{References}

1. Larsson SC \& Wolk A (2006) Meat consumption and risk of colorectal cancer: a meta-analysis of prospective studies. Int J Cancer 119, 2657-2664.

2. Norat T, Lukanova A, Ferrari P, et al. (2002) Meat consumption and colorectal cancer risk: dose-response meta-analysis of epidemiological studies. Int J Cancer 98, 241-256.

3. WCRF (2007) Food, Nutrition, Physical Activity, and the Prevention of Cancer: A Global Perspective, pp. 1-537. Washington, DC: WCRF and American Institute for Cancer Research.

4. Sugimura T, Wakabayashi K, Nakagama H, et al. (2004) Heterocyclic amines: mutagens/carcinogens produced during cooking of meat and fish. Cancer Sci 95, 290-299.

5. Sinha R, Rothman N, Brown ED, et al. (1994) Pan-fried meat containing high levels of heterocyclic aromatic amines but low levels of polycyclic aromatic hydrocarbons induces cytochrome p4501a2 activity in humans. Cancer Res $\mathbf{5 4}$, 6154-6159.

6. Stavric B (1994) Biological significance of trace levels of mutagenic heterocyclic aromatic amines in human diet: a critical review. Food Chem Toxicol 32, 977-994.

7. Bingham SA, Pignatelli B, Pollock JRA, et al. (1996) Does increased endogenous formation of $\mathrm{N}$-nitroso compounds in the human colon explain the association between red meat and colon cancer? Carcinogenesis 17, 515-523.

8. Cross AJ, Pollock JRA \& Bingham SA (2003) Haem, not protein or inorganic iron, is responsible for endogenous intestinal N-nitrosation arising from red meat. Cancer Res 63, 2358-2360.

9. Lunn JC, Kuhnle G, Mai V, et al. (2007) The effect of haem in red and processed meat on the endogenous formation of $N$-nitroso compounds in the upper gastrointestinal tract. Carcinogenesis 28, 685-690.

10. Santarelli RL, Vendeuvre J-L, Naud N, et al. (2010) Meat processing and colon carcinogenesis: cooked, nitrite-treated and oxidized high-heme cured meat promotes mucin depleted foci in rats. Cancer Prev Res 3, 852-864.

11. Parnaud G, Pignatelli B, Peiffer G, et al. (2000) Endogenous $\mathrm{N}$-nitroso compounds, and their precursors, present in bacon, do not initiate or promote aberrant crypt foci in the colon of rats. Nutr Cancer 38, 74-80.

12. Lee DH, Anderson KE, Harnack LJ, et al. (2004) Heme iron, zinc, alcohol consumption, and colon cancer: Iowa Women's Health Study. J Natl Cancer Inst 96, 403-407.

13. Larsson SC, Rafter J, Holmberg L, et al. (2005) Red meat consumption and risk of cancers of the proximal colon, distal colon and rectum: the Swedish Mammography Cohort. Int $J$ Cancer 113, 829-834.

14. Sesink ALA, Termont DSML, Kleibeuker JH, et al. (1999) Red meat and colon cancer: the cytotoxic and hyperproliferative effects of dietary heme. Cancer Res 59, 5704-5709.

15. Pierre F, Freeman A, Tache S, et al. (2004) Beef meat and blood sausage promote the formation of azoxymethaneinduced mucin-depleted foci and aberrant crypt foci in rat colons. J Nutr 134, 2711-2716.

16. Pierre F, Santarelli R, Tache S, et al. (2008) Beef meat promotion of dimethylhydrazine-induced colorectal carcinogenesis biomarkers is suppressed by dietary calcium. $\mathrm{Br} \mathrm{J}$ Nutr 99, 1000-1006.

17. Pierre F, Tache S, Petit CR, et al. (2003) Meat and cancer: haemoglobin and haemin in a low-calcium diet promote colorectal carcinogenesis at the aberrant crypt stage in rats. Carcinogenesis 24, 1683-1690.

18. Pierre F, Peiro G, Tache S, et al. (2006) New marker of colon cancer risk associated with heme intake: 1,4-dihydroxynonane mercapturic acid. Cancer Epidemiol Biomarkers Prev 15, 2274-2279.

19. Parnaud G, Peiffer G, Tache S, et al. (1998) Effect of meat (beef, chicken, and bacon) on rat colon carcinogenesis. Nutr Cancer 32, 165-173.

20. Karkare MR, Clark TD \& Glauert HP (1991) Effect of dietary calcium on colon carcinogenesis induced by a single injection of 1,2-dimethylhydrazine in rats. J Nutr 121, 568-577.

21. American Institute of Nutrition (1977) Report of the American Institute of Nutrition $A d$ boc Committee on standards for nutritional studies. J Nutr 107, 1340-1348.

22. Ohkawa H, Ohishi N \& Yagi K (1979) Assay for lipid peroxides in animal tissues by thiobarbituric acid reaction. Anal Biochem 95, 351-358.

23. Van den Berg JW, Koole-Lesuis R, Edixhoven-Bosdijk A, et al. (1988) Automating the quantification of heme in feces. Clin Chem 34, 2125-2126.

24. Sesink ALA, Termont DSML, Kleibeuker JH, et al. (2001) Red meat and colon cancer: dietary haem-induced colonic cytotoxicity and epithelial hyperproliferation are inhibited by calcium. Carcinogenesis 22, 1653-1659.

25. Bird RP (1987) Observation and quantification of aberrant crypts in murine colon treated with a colon carcinogen: preliminary findings. Cancer Lett 37, 147-151.

26. Corpet DE \& Pierre F (2005) How good are rodent models of carcinogenesis in predicting efficacy in humans? A systematic review and meta-analysis of colon chemoprevention in rats, mice and men. Eur J Cancer 41, 1911-1922.

27. Pierre F, Tache S, Gueraud F, et al. (2007) Apc mutation induces resistance of colonic cells to lipoperoxide-triggered apoptosis induced by faecal water from haem-fed rats. Carcinogenesis 28, 321-327.

28. Bull A, Bird RP, Bruce WR, et al. (1987) Effect of calcium on azoxymethane induced intestinal tumors in rats. Gastroenter$\operatorname{ology}$ 92, 1332.

29. Bruce WR, Giacca A \& Medline A (2001) Possible mechanisms relating diet to colorectal cancer risk. pp. 1-7, European Conference on Nutrition and Cancer, IARC, 21-24 June, 2001, Lyon, France.

30. Baron JA, Beach M, Mandel JS, et al. (1999) Calcium supplements for the prevention of colorectal adenomas. $N$ Engl J Med 340, 101-107.

31. Wactawski-Wende J, Kotchen JM, Anderson GL, et al. (2006) Calcium plus vitamin D supplementation and the risk of colorectal cancer. $N$ Engl J Med 354, 684-696.

32. Nelson RL, Tanure JC \& Andrianopoulos G (1987) The effect of dietary milk and calcium on experimental colorectal carcinogenesis. Dis Colon Rect 30, 947-949. 
33. Behling AR, Kaup SM, Choquette LL, et al. (1990) Lipid absorption and intestinal tumour incidence in rats fed on varying levels of calcium and butterfat. Br J Nutr $\mathbf{6 4}$, 505-513

34. Pence BC, Dunn DM, Zhao C, et al. (1995) Chemopreventive effects of calcium but not aspirin supplementation in cholic acid-promoted colon carcinogenesis: correlation with intermediate endpoints. Carcinogenesis 16, 757-765.

35. Pence BC, Dunn DM, Zhao C, et al. (1996) Protective effects of calcium from nonfat dried milk against colon carcinogenesis in rats. Nutr Cancer 25, 35-45.

36. Belbraouet S, Felden F, Pelletier X, et al. (1996) Dietary calcium salts as protective agents and laminin 1 as a biochemical marker in chemically induced colon carcinogenesis in rats. Cancer Detect Prev 20, 294-299.

37. Adell-Carceller R, Segarra-Soria M, Gibert-Jerez J, et al. (1997) Inhibitory effect of calcium on carcinogenesis at the site of colonic anastomosis: an experimental study. Dis Colon Rect 40, 1376-1381.

38. Quilliot D, Belbraouet S, Pelletier X, et al. (1999) Influence of a high-calcium carbonate diet on the incidence of experimental colon cancer in rats. Nutr Cancer 34, 213-219.

39. Molck AM, Poulsen M \& Meyer O (2002) The combination of 1alpha,25( $\left(\mathrm{OH}_{2}\right)$-vitamin $\mathrm{D}_{3}$, calcium and acetylsalicylic acid affects azoxymethane-induced aberrant crypt foci and colorectal tumours in rats. Cancer Lett 186, 19-28. 